\title{
Deformation Microstructures in Metallic Materials after Severe Plastic Deformation by Rolling with Cyclic Movement of Rolls
}

\author{
A. Urbańczyk-Gucha*, I. Bednarczyk, M. Jabeońska and K. Rodak \\ Silesian University of Technology, Faculty of Materials Science and Metallurgy, \\ Z. Krasińskiego 8, 40-019 Katowice, Poland
}

\begin{abstract}
The results of the microstructure investigations of the pure $\mathrm{Al}$ and AlMg5 alloy and pure $\mathrm{Cu}$ and $\mathrm{CuFe} 2$ alloy after the application of severe plastic deformation implemented by rolling with the cyclic movement of the rolls are presented in this paper. The rolling with the cyclic movement of the rolls was carried out at values: the rolling rate $v=1 \mathrm{rpm}$, the frequency of rolls movement $f=1 \mathrm{~Hz}$, the amplitude of rolls movement $A=1.6 \mathrm{~mm}$. Maximal values of rolling reduction at 6 passes was $\varepsilon_{h}=80 \%$. The structure of the these materials was analyzed using scanning transmission electron microscope. The quantitative studies of the substructure was performed with MET-ILO software, on the basis of images acquired on scanning transmission electron microscope. Performed substructure investigations showed that using the rolling with the cyclic movement of the rolls method can refine the microstructure of these materials to the ultrafine scale.
\end{abstract}

DOI: 10.12693/APhysPolA.130.975

PACS/topics: 62.20.F-, 61.72.Ff, 81.05.Bx, 81.40.Rs, 83.50.- -

\section{Introduction}

A lot of the scientific investigations are focused on the research of new materials with a high efficiency and new technologies for their production [1-6]. Over the last two decades, a number of techniques were adopted to processing metals and alloys to grain refinement to nanoand sub-micrometer scale. Nanograined and ultrafinegrained materials are interesting because they have better mechanical and physical properties than the materials with micrometer grained structure [5-10]. In the group of materials which are often processed by using severe plastic deformation (SPD) are pure aluminium and aluminium alloys, which play important role in automotive and aerospace engineering due to their good corrosion resistance, good machinability and weldability. The second group of non-ferrous materials, which play a key role in electric engineering are copper and copper alloys. In literature the effectiveness of SPD methods has been revealed for a pure $\mathrm{Al}$ [7-13], $\mathrm{Al}-\mathrm{Mg}$ alloys [13, 14], pure $\mathrm{Cu}[11,13-19]$ and $\mathrm{Cu}-\mathrm{Fe}$ [20] alloys. Recent works have demonstrated $[21,22]$ that one of the method which can be used for SPD processing is rolling with cyclic movements of rolls (RCMR). This original method of deformation has been patented in Silesian University of Technology, Faculty of Materials Engineering and Metallurgy in Poland [. In RCMR technique, the rolled strip is deformed by reducing the height and additionally the material is affected by movement in a direction perpendicular to the main direction of rolling. By repeating this procedure, very high strains have been introduced

\footnotetext{
* corresponding author; e-mail: Anna.Urbanczyk-Gucwa@polsl.pl
}

into material and significant structural refinements has been achieved. In literature, there is lack of information about how the RCMR processing influence on refinement structure of mentioned materials and what is the effectiveness of the method in refinement structure compared with another SPD method. The $\mathrm{Al}, \mathrm{Al}-\mathrm{Mg}$ and $\mathrm{Cu}, \mathrm{Cu}^{-}$ Fe systems were chosen for the study for two reasons: $\mathrm{Al}$ and $\mathrm{Cu}$ - representative face-centred cubic metals with different value of stacking fault energy and can be readily produced by SPD method, whereas alloys are much more stable thermally and mechanically in comparison with pure metals. For this reason the alloys are most promising for manufacturing nanostructured material for various applications.

\section{Experimental}

Investigations were performed on: pure $99.7 \%$ aluminium, AlMg5 alloy containing $5 \mathrm{wt} \% \mathrm{Mg}$, pure copper (M1E) and $\mathrm{CuFe} 2$ alloy containing 2 wt\% Fe. The samples after heat treatment (annealing for metals and solutioning for alloys) were processed by using RCMR method. Scheme of RCMR method is shown in Fig. 1a. All tests using the RCMR method were conducted at room temperature. In our experiments, deformation by RCMR method was realized at parameters: rolling reduction $\left(\varepsilon_{h}\right)=80 \%$, rolling rate $v=1 \mathrm{rpm}$, amplitude of rolls movement $A=1.6 \mathrm{~mm}$, and the frequency of rolls movement $f=1 \mathrm{~Hz}$. Process was realized in 6 passes. The total effective strain $\left(\varepsilon_{f t}\right)$ was 6.7 . Microstructural analysis were performed using a Hitachi scanning transmission electron microscopy (STEM) according with procedure presented in Fig. 1b. The detailed quantitative investigations of the ultrafine-grained structures were performed using MET-ILO software. 
a)

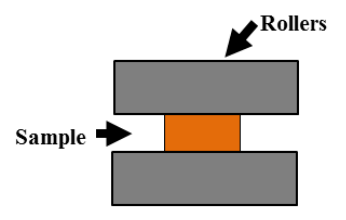

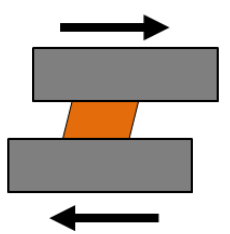

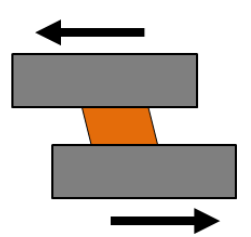

b)

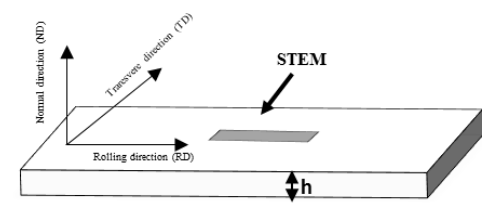

Fig. 1. Scheme of RCMR process (a) and the place of cutting and microstructure observation (b).

\section{Results and discussion}

\subsection{Pure Al and AlMg5 alloy}

Figure $2 \mathrm{a}$ and $\mathrm{b}$ shows the microstructure of pure $\mathrm{Al}$ and AlMg5 alloy after rolling with the cyclic movement of rolls. In Al microstructure there were observed well formed grains/subgrains with low dislocations density in the interior (Fig. 2a). Furthermore in the
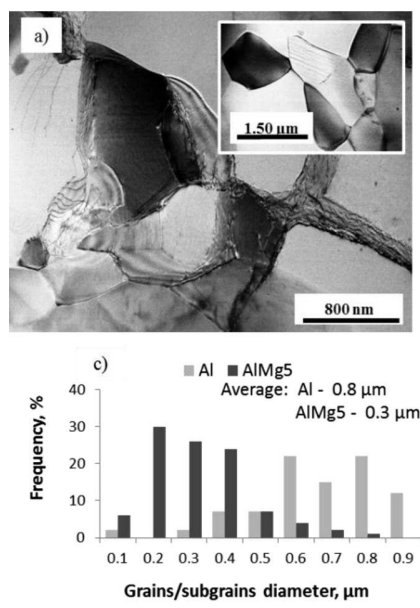

Fig. 2. Microstructure of pure $\mathrm{Al}$ after RCMR processing (a), microstructure of AlMg5 alloy after RCMR processing (b), distribution of grain/subgrain diameter (c), distribution of shape index $(d)$.

microstructure are visible polygonal dislocation boundaries. Some boundaries are curved and strong spreading of thickness extinction contours in Fig. 2a indicates high elastic stress near the non-equilibrium boundaries. In $\mathrm{Al}-$ Mg alloy processed by RCMR there are observed tangles of dislocations in matrix. Microstructure revealed irregular grains and poorly defined grain boundaries. This means that many of the boundaries are in high-energy non-equilibrium configurations (Fig. 2b). It should be noted that in AlMg5 alloy the development of ultrafine grained structures is accompanied by increase in dislocation density and the microstructure refinement process is mainly characterized by subgrains with small misorientation angles. According with MET-ILO measurement, the average grains/subgrains size for pure $\mathrm{Al}$ and AlMg5 alloy were $0.8 \mu \mathrm{m}$ and $0.3 \mu \mathrm{m}$, respectively (Fig. 2c), and average value of shape index were 0.7 and 0.5 for pure $\mathrm{Al}$ and AlMg5 alloy (Fig. 2d). Grain/subgrain size distributions for $\mathrm{Al}$ and AlMg5 alloy are significantly different. Many of grains with the dimensions of $0.6-0.9 \mu \mathrm{m}$ exist in Al but in AlMg5 alloy the fraction of grains with dimensions of $0.2-0.4 \mu \mathrm{m}$ is high and reaches about $75 \%$ (Fig. 2c). The fraction of shape index in range of $0.9-1$ (most equiaxed grains/subgrains) for $\mathrm{Al}$ was about $30 \%$ but for AlMg5 alloy the fraction was only 8\% (Fig. 2d).

Results of $\mathrm{Al}$ processing by RCMR showed that dynamic processes take place during deformation which include annihilation of dislocation within subgrains and rearrangement of dislocations to form grain boundaries. This process may also include absorption of dislocation into grain boundaries. Finally, it was shown that the grain size was reduced to about $0.8 \mu \mathrm{m}$. The addition of $5 \mathrm{wt} \% \mathrm{Mg}$ to $\mathrm{Al}$ is effective to refine the grain size. The grain size reduction was attained up to $0.3 \mu \mathrm{m}$. The solute atoms has a very strong effect on inhibiting recovery, for this reason less dynamic boundary migration occur and the lamellar (elongated) structure of grains/subgrains are dominating in microstructure.

\subsection{Pure $\mathrm{Cu}$ and $\mathrm{CuFe2}$ alloy}

Figure $3 \mathrm{a}$ and $\mathrm{b}$ shows the microstructure of pure $\mathrm{Cu}$ and $\mathrm{CuFe} 2$ alloy after rolling with the cyclic movement of rolls. The observations indicate that grains interiors can be free from dislocations or have numerous dislocations stored (Fig. 3a). Many grains about $\approx 100 \mathrm{~nm}$ in size are completely free of dislocations and boundaries are curved. Finally, the grain size of $\mathrm{Cu}$ produced in these experiments by RCMR was $0.5 \mu \mathrm{m}$ (Fig. 3c). The processed sample of $\mathrm{CuFe} 2$ alloy exhibits elongated subgrain/grain structure with high dislocation density in the interior (Fig. 3b). The boundaries are often mixtures of low angle and high angle boundaries. STEM/nano diffraction observations revealed that locally now ultrafine-grain (UFG) grains with high angle boundary were created (Fig. 3b). The grain/subgrain size of the $\mathrm{CuFe} 2$ alloy is much smaller than that of the $\mathrm{Cu}$. According with METILO measurement, the average grains/subgrains size for $\mathrm{CuFe} 2$ alloy was $0.3 \mu \mathrm{m}$. In CuFe2 alloy more than $70 \%$ of analyzed grains/subgrains have size in the range of $0.1-$ $0.2 \mu \mathrm{m}$. For $\mathrm{Cu}$ the grain size distribution is different and in the microstructure dominate grains/subgrains with diameter in the range of $0.2-0.5 \mu \mathrm{m}$. Cyclic deformation causes formation of dislocation boundaries which propagate in different direction due to activity of a number of slip system. The STEM images revealed that ultrafine grained structure with near equiaxed grains/subgrains were easy created in $\mathrm{Cu}$ during RCMR method. The average value of shape index was 0.7 and the fraction of shape index in the range of $0.9-1$ was about $30 \%$ (Fig. 3d). But the reduced rate of dynamic boundary 
migration observed especially in $\mathrm{CuFe} 2$ alloy results in a far more elongated grain/subgrain structure (Fig. 3d) and the average value of shape index was 0.5 and the fraction of shape index in the range of $0.9-1$ was about $5 \%$.
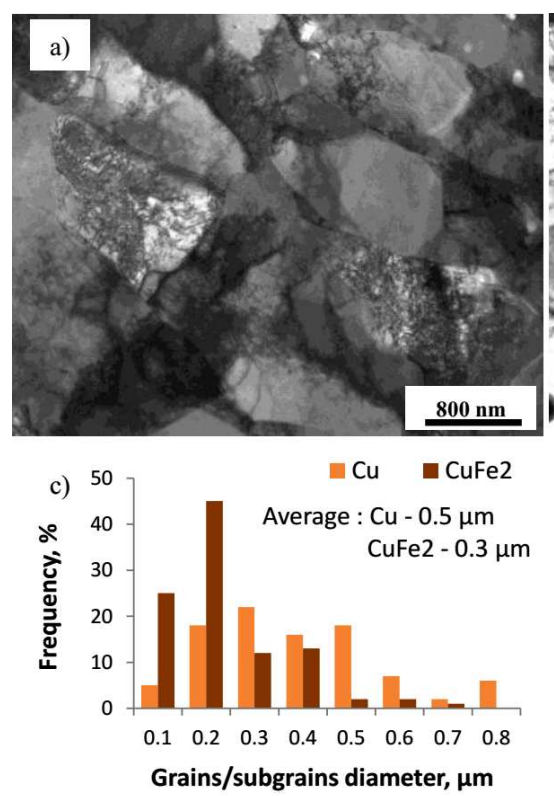
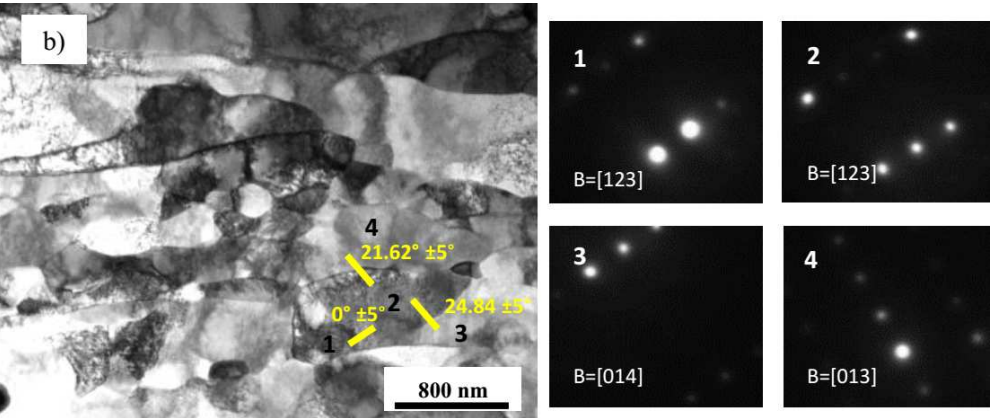

d)

$\mathrm{Cu} \square \mathrm{CuFe2}$

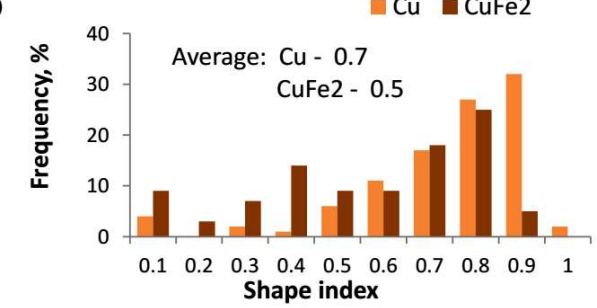

Fig. 3. Microstructure of pure $\mathrm{Cu}$ after RCMR processing (a), microstructure of $\mathrm{CuFe} 2$ alloy after RCMR processing (b), distribution of grain/subgrain diameter (c), distribution of shape index (d).
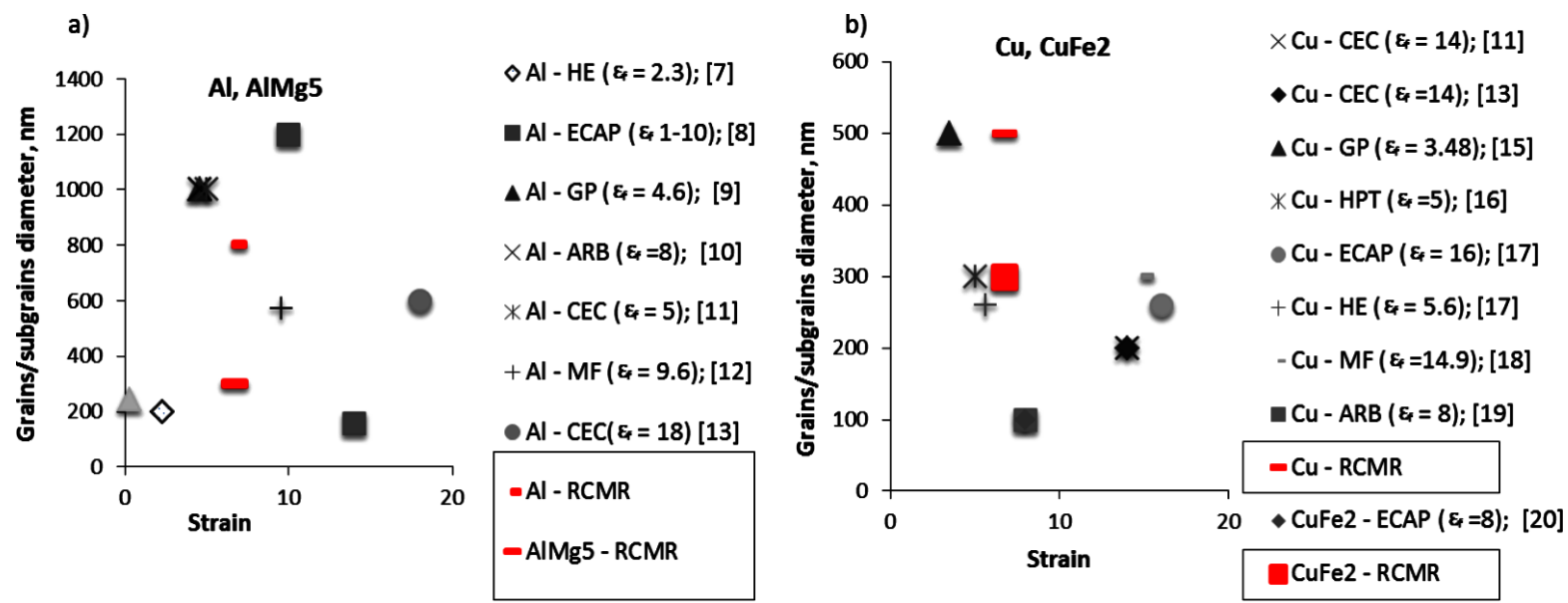

Fig. 4. The grain/subgrain size of $\mathrm{Al}$ and AlMg5 alloy (a) and $\mathrm{Cu}$ and $\mathrm{CuFe} 2$ alloy (b) measured by TEM vs. strains of different SPD method.

A comparison of the present result of RCMR with the other results were presented in Fig. 4. The RCMR process is just as effective in creating refinement structures as the another SPD techniques. RCMR with a strain $\left(\varepsilon_{f t}\right)$ of about $\approx 7$ shows similar results as the CEC with a strain of $\approx 5$ in Al refinement. In AlMg5 alloy after deformation about $\approx 14$, the mean width of the microbands was $156 \mathrm{~nm} \mathrm{[13].} \mathrm{In} \mathrm{our} \mathrm{experiment} \mathrm{the} \mathrm{average} \mathrm{value}$ of grains/subgrain size in AlMg5 alloy were about twice lower but the strain was twice smaller, too (Fig. 4a). The result obtained for $\mathrm{Cu}$ is quite close to that of $\mathrm{Cu}$ processed by groove pressing (GP) method to a strain of about $\approx 4$. Equal-channel angular pressing (ECAP) process with strain about $\approx 8$ is more effective than the $\mathrm{RCMR}$ process with strain $\approx 7$ in refinement structure of $\mathrm{CuFe} 2$ (Fig. 4b).

Based on our experiment should be noted that addition of alloying elements to $\mathrm{Al}$ and $\mathrm{Cu}$ matrix very effectively decreases the rate of recovery and, in the result, this situation leads to decrease in grain/subgrain size. Obtained results are in accordance with literature [7-20]. Enhanced mobility of dislocations in $\mathrm{Al}$ and $\mathrm{Cu}$ due to 
the lack of alloying elements to hinder the dislocation movement results in weakening of grain refinement. Additionally in case of $\mathrm{Al}$ for which the stacking fault energy (SFE) is large $\left(200 \mathrm{~mJ} / \mathrm{mm}^{2}\right)$ [6], the mobility including cross slip and climb of dislocation occurs more easy than the metals with medium stacking fault energy (SFE for $\mathrm{Cu}=50 \mathrm{~mJ} / \mathrm{mm}^{2}$ ) [6], in the result the level of structure refinement in $\mathrm{Al}$ by RCMR is a little smaller than $1 \mu \mathrm{m}$.

\section{Summary}

The aspects of microstructure refinement of the metallic materials as: $\mathrm{Al}, \mathrm{AlMg} 5, \mathrm{Cu}$ and $\mathrm{CuFe} 2$ with using rolling with the cyclic movement of rolls method was discussed. The main results are as follows:

1. RCMR method allows to produce UFG materials. The RCMR process is just as effective in creating refinement structures as the another SPD process.

2. Grain refinement was more significant for alloys than for pure metals. The average grain/subgrain size was: $0.8 \mu \mathrm{m}$ and $0.3 \mu \mathrm{m}$ for $\mathrm{Al}$ and $\mathrm{AlMg} 5$ respectively and $0.5 \mu \mathrm{m}$ and $0.3 \mu \mathrm{m}$ for $\mathrm{Cu}$ and $\mathrm{CuFe} 2$, respectively.

3. In pure $\mathrm{Al}$ and $\mathrm{Cu}$ enhanced recovery reduces the accumulation of dislocations during the process but instead increases the fraction of high angle boundary in microstructure, while recovery is significantly inhibited by the dilute addition of $\mathrm{Mg}$ in $\mathrm{Al}$ and $\mathrm{Fe}$ in $\mathrm{Cu}$.

\section{Acknowledgments}

This work was carried out with a project No. UMO2013/09/B/ST8/01695.

\section{References}

[1] D. Stróż, G. Dercz, J. Pawlicki, J. Palka, Solid State Phenom. 163, 137 (2010).

[2] K. Rodak, J. Pawlicki, J. Mater. Sci. Technol. 27, 1083 (2011).

[3] B. Dybowski, B. Adamczyk-Cieślak, K. Rodak, I. Bednarczyk, A. Kiełbus, J. Mizera, Solid State Phenom. 229, 3 (2015).
[4] Ł. Poloczek, B. Dybowski, M. Łuszczak, A. Kiełbus, Archiv. Foundry Eng. 15, 89-92 (2015).

[5] M. Lewandowska, K.J. Kurzydłowski, Mater. Character. 55, 395 (2005).

[6] B.L. Li, N. Tsuji, N. Kamikawa, Mater. Sci. Eng. A 423, 331 (2006).

[7] K.J. Kurzydłowski, H. Garbacz, M. Richert, Adv. Mater. Sci. 8, 129 (2004).

[8] Y. Iwahashi, Z. Horita, M. Nemoto, T.G. Langdon, Acta Met. 45, 4733 (1997).

[9] A. Krishnaiah, U. Chakkingal, P. Venugopa, Scr. Mater. 52, 1229 (2005).

[10] M. Eizadjou, HD. Manesh, K. Janghorban, J. Alloys Comp. 474, 406 (2009).

[11] M. Richter, Engineering of nanomaterials and ultrafine grained structures, Uczelniane Wydawnictwo Naukowo Techniczne, Kraków 2006, (in Polish).

[12] K. Rodak, K. Radwański, R. Molak, Solid State Phenom. 176, 21 (2011).

[13] M. Richert, B. Leszczyńska-Madej, J. Richert, S. Boczkal, Rud. Met. Niez. R55, 284 (2010).

[14] J. Skorupka, K. Rodak, Rud. Met. Niez. R58, 143 (2013).

[15] A. Krishnaiah, U. Chakkingal, P. Venugopal, Mater. Sci. Eng. 410-411, 337 (2005).

[16] N. Lugu, N. Llorca, C. Marrero, M. Jose, Z. Horita, Mater. Sci. Eng. 477, 366 (2008).

[17] Z. Pakieła, H. Garbacz, M. Lewandowska, A. Drużycka-Wiencek, M. Suś-Ryszkowska, W. Zieliński, K.J. Kurzydłowski, Nukleonika 51, 19 (2006).

[18] K. Rodak, R. Molak, Z. Pakieła, Phys. Status Solidi C 7, 1351 (2010)

[19] M. Shaarbaf, M.R. Toroghinejad, Mater. Sci. Eng. 473, 28 (2008).

[20] H. Cao, J.Y. Min, S.D. Wu, A.P. Xian, J.K. Shang, Mater. Sci. Eng. A 431, 86 (2006).

[21] Z. Cyganek, K. Rodak, F. Grosman, Archiv. Civ. Mech. Eng. 13, 7 (2013).

[22] A. Urbańczyk-Gucwa, I. Bednarczyk, A. Płachta, K. Rodak, J. Sobota, W. Głuchowski, Z. Rdzawski, Inz. Mat. 5, 233 (2015).

[23] Patent no PL 203220 B1. 